\title{
DOMINAÇÃO MASCULINA E VIOLÊNCIA SIMBÓLICA NA ATIVIDADE DE CORTE DE CANA-DE-AÇÚCAR
}

\section{MALE DOMINATION AND SYMBOLIC VIOLENCE IN THE SUGARCANE CUTTING ACTIVITY}

\begin{abstract}
Alessandro Gomes Enoque
Uberlândia (UFU)

Uberlândia, MG, Brasil

Email: alessandroenoque@gmail.com

\section{Alex Fernando Borges}

Professor Assistente da Universidade Federal de Uberlândia (UFU).

Uberlândia, MG, Brasil

Email: alexfborges@gmail.com

\section{Ana Carolina Assis Sampaio}

Bolsita de Iniciação Científica na Universidade Federal de Uberlândia (UFU).

Uberlândia, MG, Brasil

Email: rosendo.sebrae@gmail.com

Aline Cordeiro dos Santos

Uberlândia, MG, Brasil

Email: alinesantos@gmail.com

\section{RESUMO}

Este trabalho tem, como objetivo principal, analisar o processo de dominação masculina (no nível estrutural e simbólico) e como que ele se legitima através da violência simbólica no âmbito da atividade de corte de cana-de-açúcar na microrregião brasileira de Ituiutaba/MG. No que tange a metodologia, de natureza qualitativa, foram realizadas 15 entrevistas com trabalhadores e gestores inseridos neste tipo de atividade. Verificou-se, a partir disto, como ocorrem os processos de divisão sexual do trabalho, bem como a dominação masculina neste campo de atividade. Percebeu-se, ainda, a forma como a violência (resultante desta dominação) se exercita dentro do campo social.
\end{abstract}

Pós-Doutorado em Sciences Humaines pela École des Sciences de la Gestion (ESQ) da Université du Québec à Montréal (UQAM).

Doutor em Ciências Humanas (Sociologia e Ciência Política) pela Universidade Federal de Minas Gerais (UFMG). Mestre em

Administração pela Universidade Federal de Minas Gerais (UFMG). Atualmente, é professor adjunto da Universidade Federal de

Doutorando e Mestre pelo Programa de Pós-Graduação em Administração (PPGA) da Universidade Federal de Lavras (UFLA).

Graduada em Administração pela Universidade Federal de Uberlândia (UFU) e Bolsista de Iniciação Científica.

Palavras-chave: Dominação masculina. Violência simbólica. Cana-de-açúcar. Trabalho. Gênero.

\section{ABSTRACT}

This work has as main objective to analyze the maledominated process (structural and symbolic level) and how it is legitimized through the symbolic violence within the sugarcane cutting activity in the brazilian micro- Ituiutaba / MG. Regarding the methodology qualitative, were conducted 15 interviews with workers and managers entered into this type of activity. It was from this, as they occur the sexual division of labor processes as well as male domination in this field of activity. It was noticed also how violence (resulting from this domination) exercise within the social field.

Keywords: Male domination. Symbolic Violence. Sugarcane. Work. Gender.

Data de submissão: 29 de outubro de 2015.

Data de aprovação: 7 de março de 2019. 


\section{INTRODUÇÃO}

O estado brasileiro de Minas Gerais, desde o ano de 2009, é caracterizado como o segundo maior produtor de cana-de-açúcar do Brasil, conforme dados do IBGE (Instituto Brasileiro de Geografia e Estatística). Na microrregião de Ituiutaba/MG, tal atividade encontra bastante importância, contando com 84 estabelecimentos agropecuários voltados para a produção da lavoura temporária da cana-de-açúcar na região.

Participam dessa atividade trabalhadores, em sua maioria migrantes, que tem por atividade principal o corte sazonal da cana-de-açúcar. Percebe-se que entre esses trabalhadores, destaca-se uma grande quantidade de mulheres que buscam sua sobrevivência por meio da coleta dos restos de cana-de-açúcar (bitucas) deixados para trás pela atividade do corte (os homens estão inseridos, em sua maioria, no corte de cana).

Diante do exposto acima, o estudo proposto nesse artigo busca compreender os conceitos de dominação masculina e violência simbólica na atividade de corte de cana-de-açúcar na região de Ituiutaba/MG. Este trabalho pretende analisar, ainda, como ocorre a dominação, tanto a nível estrutural como simbólico bem como a violência exercida e perpetuada dentro desse campo.

\section{ASPECTOS CONCEITUAIS: DOMINAÇÃO MASCULINA E VIOLÊNCIA SIMBÓLICA}

A violência pode ser exercida de diversas formas e em diversos níveis, podendo ser: física, psíquica, sexual, verbal, simbólica, entre outras. Podendo ainda, ser destinada a um indivíduo ou a um grupo. Contudo, o senso comum nos orienta a pensar apenas na violência física. Esta visão pode ser entendida como ultrapassada uma vez que são identificados em um estudo da OMS (ROSA; BRITO, 2009). Outros tipos de violência que trazem lesões tão graves quanto os tipos de violência supracitados (ROSA; BRITO, 2009).

Dos tipos descritos no estudo da OMS (ROSA; BRITO, 2009), discutiremos, fundamentalmente, aquele relacionado à violência simbólica. $O$ destaque ao simbólico não se apresenta no objetivo de minimizar ou se fazer esquecer da violência física tão presente na sociedade (e visíveis também no processo de legitimação de força) como espancamentos, homicídios, torturas, etc. Todavia, para Bourdieu (2002) a violência simbólica retrata uma "violência doce" que de tão naturalizada se apresenta de forma sutil e quase imperceptível.

A violência surge com a necessidade de legitimar força em determinado campo social, e no meio simbólico, se faz na legitimação da produção do capital simbólico. Os campos, por serem campos estruturados, possuem cargos e funções específicos que existem inerentes a quem os esteja ocupando. Desta forma, há uma disputa para quem irá deter o poder e ao tratar da violência simbólica, a disputa entre o grupo é pelo capital simbólico. Ou seja, o objetivo passa a ser reter recursos simbólicos.

Nesse sentido, para que se exerça a vontade do dominante, que detém o poder dentro de determinado grupo, o exercício da violência se faz relevante, sendo usada para forçar um comportamento, comportamento exigido e característico dos dominantes, para se estabelecer uma "coesão". E esse "papel de controle" exercido pela violência, é atuado também pelos símbolos. 
Os símbolos apresentam-se no "conjunto de ideologias, imagens e valores" (ROSA; BRITO, 2009). Desta forma, podemos entender que os símbolos estão presentes em todos os aspectos da nossa vida cotidiana e impregnado nos rituais, no comportamento e no pensamento. Sendo assim, comunicamos-nos através de símbolos, que se apresentam nas mais diversas formas. Inclusive transmite os ritos e comportamentos comuns a um determinado grupo. Pode-se, dizer então, que o mundo possui o ethos que corresponde as ideologias e princípios que regem vida cotidiana e o hexis que representa a disposição corpórea de tais princípios, como expressão e postura (BONNEWITZ, 2003 apud ROSA; BRITO, 2009).

É através desses conceitos que construímos os métodos de percepção do mundo, que ditam nossas práticas, na produção e reprodução dos conceitos tradicionais estabelecidos e que são difundidos através dos símbolos. Nesse sentido, que se é percebido o habitus. O Habittus é "uma espécie de máquina transformadora que faz com que nós 'reproduzamos' as condições sociais da nossa própria produção" (ROSA; BRITO, 2009. P 634). Desta forma, com o habittus se perpetua as condições sociais e comportamentos estabelecidos tradicionalmente, que são transmitidos de maneira simbólica, em diversos níveis, seja nos valores ou no comportamento.

A partir desta análise, é possível entender, como se constrói a violência simbólica. Os aspectos simbólicos são construídos por aqueles que querem deter o poder dentro do grupo, dessa forma, os dominantes podem assim transmitir a imagem que desejam à imagem ideal, a correta, a doxa. Desta forma, a doxa se apresenta como o próprio senso comum, são atitudes programadas ditas como certas, "elemento de reprodução da ordem social" (ROSA; BRITO, 2009). Nesse sentido, o ethos, o hexis e o habittus, pertencem a doxa, e para a manutenção dessa ordem social, é usada uma "ação pedagógica", algo que repreenda e ensine o comportamento e pensamento adequado, e, portanto, o dominante usa da força e da opressão, para manter a ordem e a coesão.

É de se entender então, que a violência simbólica se manifesta de maneira doxica, naturalizada. Essa forma de agressão, também entendida como uma dominação ocorre de maneira sutil, sendo imperceptível aos dominados. Sendo assim, os que são oprimidos por esta violência se submetem de maneira voluntária, pois faz parte das "disposições duráveis" (habitus) e da "cultura dominante" (doxa). (BOURDIEU, 2002).

Esse tipo de violência só ocorre com a "permissão" do violentado, ou seja, deve haver uma "concessão" por parte do subordinado. Essa "voluntariedade" é entendida pelo grupo como casual, habitual, que segue de maneira natural, pois está presente no cotidiano. Na ótica de Rosa; Brito (2009, P 637), pode ser entendido como uma 'violência silenciosa' '[...] que se manifesta, sutilmente, nas relações sociais e resulta de uma dominação [...]". A violência simbólica é então, uma relação entre dominante e dominado em que o dominado se submete de forma naturalizada. Desta forma, tal submissão não é claramente visível por estar no doxa, ou seja, na "atitude natural da vida diária" (ROSA; BRITO, 2009).

Nessa perspectiva, Bourdieu (2002), argumenta que a violência simbólica é o efeito da dominação, se exerce sobre os corpos sem qualquer coerção física, através de esquemas de percepção. Sendo assim, é possível associar a violência simbólica com a ideia dominação decorrente da estrutura social androcêntrica, "[...] que confere aos homens a melhor parte [...]" (BOURDIEU, 2002, p.51). A partir desta concepção, entende-se que a ordem social atribui ao homem o papel de dominação, admitindo-o como superior. Através da incorporação das relações de poder, a dominação, presente no habitus, se manifesta e se reproduz naturalmente em elos e vínculos sociais. 
Sendo o homem, então quem detém o poder, deve liderar a manter e coesão dentro do âmbito social, faz-se necessário legitimar a soberania dentro do campo. Para impor sua superioridade, para ser reconhecido como dominante, e, portanto, masculino, faz-se o uso da violência. A masculinidade é, assim, associada ao ideário da brutalidade. Visto que para obter o respeito e poder no grupo é necessário atribuir símbolos masculinos. O homem se vê ainda com uma carga social onde precisa legitimar e provar sua virilidade. Nesse sentido, produção social expressa uma associação entre virilidade e violência, em que comportamentos violentos e agressivos são entendidos como símbolos masculinos e constata sua hombridade.

Sendo assim, para autenticação da superioridade do ser masculino, a brutalidade associada com a legitimação da masculinidade aparece como uma forma de autoridade e comando, fazendo com que o homem detenha a força dentro do campo social. Portanto, o masculino dotado da 'carga' de ser o líder, o chefe, o provedor, muitas vezes atribui agressões como uma maneira de manter sua autoridade oprimindo comportamentos que vão contra a proposta dominante.

Segundo Alcadipani (2010, p 96) “[...] A sexualidade, para o homem, está ligada ao poder [...]”. Nesse sentido, é possível compreender a posição agressiva na qual o homem deve portar para ser considerado viril e, portanto, se estabelecer como masculino na sociedade. É possível, então, comprovar a associação entre a violência simbólica engrenada nos corpos e a representação falocentrica nas estruturas sociais.

A partir dessa análise, é possível entender como ocorre o processo de manifestação na violência simbólica que apesar de seu caráter subliminar, expressa-se nas mais diversas formas de atitudes da vida cotidiana. É possível entender ainda como a violência, associada a ideia de masculinidade e brutalidade, expõe-se como resposta a uma dominação do campo masculino sobre o feminino. Nesse sentido, através da reprodução dos comportamentos androcêntricos há a perpetuação da ordem masculina ortodoxa, reforçando as abordagens simbólicas associadas ao caráter masculino, engendrados nas estruturas sociais estabelecidas. A violência resume-se, então, ao método de produção de corpos dóceis (FOUCAULT, 1987. PRESTES MOTTA, 1986 APUD ALCADIPANI, 2010) e como forma de manutenção do ideal tradicional falocentrico.

\section{METODOLOGIA}

Este estudo é de natureza qualitativa. Segundo Cooper; Schindler (2011), a pesquisa qualitativa inclui um conjunto de técnicas interpretativas que procuram descrever, traduzir, dar um significado a certos fenômenos ocorridos ao meio estudado. Assim, a pesquisa qualitativa pretende informar ao pesquisador como o processo ocorre e o que significa.

A seleção da amostra obedeceu ao critério de amostragem não-probabilística intencional. Nessa perspectiva, Barros; Lehfeld (2007, p. 103) afirmam que "[...] amostra intencional ou seleção racional: de acordo com uma estratégia adequada, os elementos da amostra são escolhidos. Estes se relacionam intencionalmente com as características estabelecidas". Para fins desta pesquisa, foram buscados, assim, trabalhadores na atividade de corte de cana-de-açúcar na região de Ituiutaba/MG.

No que diz respeito à técnica de coleta de dados utilizada, optou-se pela entrevista semi-estruturada. Embora algumas das definições sobre entrevista semi-estruturada abrangem a compreensão dos significados que os entrevistados dão as questões respondidas referentes ao tema, Godoi; Mello; Silva (2010, p. 134) 
abordam que "[...] a entrevista é utilizada para recolher dados descritivos na linguagem do próprio sujeito, possibilitando ao investigador desenvolver uma ideia sobre a maneira como os sujeitos interpretam aspectos do mundo". Sendo assim, é possível ressaltar que o investigador use um roteiro prévio de alguns pontos que acredite serem importantes para a pesquisa, deixando o entrevistado a vontade para que ele possa construir o seu próprio discurso. Dessa forma, realizamos 15 entrevistas, que foram gravadas e transcritas, a fim de serem recuperadas e analisadas segundo o método proposto e o objetivo da pesquisa.

Por fim, o procedimento de análise de dados abordado inseriu-se no campo da análise de conteúdo. Segundo Barros; Lehfeld (1990) está é uma técnica que tem como objeto de estudo a linguagem, na qual constitui um conjunto de instrumentos metodológicos que asseguram a objetividade. Conforme pode ser observada em Campos (2007, p.265), a análise de conteúdo exige "[...] que o pesquisador esteja aberto para a compreensão de que as palavras têm muito mais a dizer. Não trata de adivinhar, [...] mais sim de ver no conteúdo o discurso do ser humano".

\section{ANÁLISE DOS DADOS}

Podemos observar, a partir da análise dos fragmentos discursivos (001) e (002) que há uma clara divisão sexual do trabalho no interior da atividade de corte de cana-de-açúcar na microrregião de Ituiutaba/MG. Enquanto a atividade de corte de cana é, essencialmente, masculina, o trabalho da "bituca" apresenta fortes contornos femininos. Convêm destacar que tal divisão se estende, ainda, a uma outra dimensão importante, uma vez que os dois grupos (cortadores e bituqueiras) não trabalham juntos no mesmo espaço (fragmentos (003) e (004)). Há, por assim dizer, uma separação física destes dois grupos que não se encontram durante o decurso do trabalho.

(001) [...] a tá, cortador tem mais homens[...] Os cortador num bituca não. (ENTREVISTADA 06)

(002) [...] No corte de cana é bem pouco, são poucas. Agora as mulheres se concentram mais no serviço da bituca. (ENTREVISTADO 02)

(003) [...] É, mas num põe junto com nóis não. Eles vai pra uma área e nóis vai pra outra... então é em áreas separada. (ENTREVISTADA 07)

(004) [...] só tem um grupo de mulheres, por exemplo, as bituqueiras ate mesmo quando elas estão capinando elas trabalham separadas. (ENTREVISTADO 01)

Ao aprofundarmos a análise, em uma tentativa de compreender a razão da divisão sexual do trabalho no espaço estudado, observamos que um dos argumentos utilizados por homens e mulheres está relacionado a "rudeza" do trabalho realizado, bem como a necessidade de uso da força física. Conforme pode ser visto no fragmento (005), há uma clara compreensão da atividade do corte de cana-de-açúcar, por parte da entrevistada, enquanto um serviço essencialmente pesado, fortemente associado a força física. Há, ainda, a 
ideia de que tal associação (trabalho masculino e força física) é componente "natural" na realidade pesquisada e em nossa sociedade. Além disto, a atividade do corte é, ainda, associada a uma dimensão de sofrimento, retratada pela entrevistada, enquanto um "drama".

(005) [...] o corte de cana uai, é trabalho de homem porque é serviço pesado. Porque os homens já são acostumados a cortar, e a gente ver muito assim drama, e eu acho que é um serviço muito pesado. [...] bituca é serviço de mulher porque é um serviço maneiro, bituca é um serviço maneiro. (ENTREVISTADA 04)

No que diz respeito ao trabalho da "bituca", há uma compreensão do mesmo enquanto uma atividade aparentemente "leve", conforme pode ser observado no uso do termo "maneiro" (fragmento (005)) por parte da entrevistada. Tal termo (maneiro) denotaria, assim, uma certa facilidade no exercício da atividade, que não necessitaria de força física extrema. Cabe destacar que, tal realidade pode ser comprovada, ainda, na medida em que, na ocorrência de picos de produção (fragmentos (006) e (007)), são alocados "homens velhos" que teriam, como particularidade, também, a ausência de força física. Assim, os "homens novos", representantes de virilidade e força seriam designados para o corte enquanto que "os senhores", seriam caracterizados com aspectos femininos (fragilidade), e encaminhados para o "espaço da mulher" ("bituca")( fragmento (008)).

(006) [...] Não, quando tá muito apertada, aí eles põe os homens pra bitucar também [...]. (ENTREVISTADA 06)

(007) [...]Mas quando é preciso até os cortadores é obrigado a ir, quando precisa o trem ta apertado, e a usina estar precisando de cana e o serviço não estar rendendo direito e eles pegam ate cortador pra ajudar a bitucar. (ENTREVISTADA 07)

(008) [...] São, são os senhor [...] Menino novo é... o corte né. Fica no corte de cana.[...](ENTREVISTADA 07)

(009) [...] não, sempre divide igual. Sempre divide igual mas sempre joga as mulheres em serviços pesados. (ENTREVISTADA 05)

Ao nos atentarmos ao termo "obrigado" no fragmento (007), é possível observar que o homem é alocado na "bituca" de maneira involuntária, sendo o cortador, designado a essa função, apenas em momentos em que há um acúmulo de trabalho. No que tange a divisão de atividades dentro do espaço em que homens e mulheres trabalham juntos, vale ressaltar que apesar da entrevistada (fragmento 009) declarar que a divisão é sempre igualitária, a mesma logo se contradiz afirmando que "[...] sempre joga as mulheres em serviços mais pesados [...]" deixando evidente a desigualdade dentro do âmbito do trabalho.

A partir da análise da categorização sexual dos espaços de trabalho (cortadores homens e bituqueiras mulheres) podemos identificar a incorporação dos atributos masculinos e femininos nos seus respectivos 
espaços. Sendo assim, podemos reconhecer a associação entre as concepções de vulnerabilidade e os espaços femininos. Ao aprofundarmos o nível de análise, observamos, no entanto, que tal atividade ("bituca") não é, exatamente, "fácil", apresentando contornos, em certos momentos, até dramáticos (fragmentos (010) e (011))

(010) [...] trabalhei grávida. Tive cinco ameaças de perder a minha menina, por causa do serviço né [...] porque era aquele agacha e levanta [...] se não fosse por deus eu tinha perdido ela. (ENTREVISTADA 01)

(011) [...] o que é difícil são as condições [...] o sol quente, o agachar e o levantar, dói as pernas [...] a cabeça as vezes [...] (ENTREVISTADA 04)

Em uma perspectiva complementar, Bourdieu (2002) aponta que, na divisão sexual do trabalho, seria concedido ao homem o mais vantajoso ou satisfatório. Na realidade pesquisada, podemos identificar tais diferenças na dimensão financeira e nas políticas de progressão. No que tange ao âmbito financeiro, é possível pontuar, a partir da análise dos fragmentos (012), (013), (014) e (015), uma clara distinção dos honorários entre os gêneros, seja nos métodos de remuneração, seja na oscilação do valor pagamento. Quanto aos honorários, podemos observar, de acordo com os trechos (012) e (013), que as bituqueiras recebem por dia um valor correspondente a vinte e nove reais, sendo acrescido, ainda, sobre a remuneração total, o valor da cesta básica. É relevante apontar, ainda, que o plano de execução na atividade da bituca é 'cinco por um', ou seja, trabalha-se cinco dias consecutivos e em seguida é fornecido um dia de descanso. Nesse sentido, os dias ditos como não úteis (sábados, domingos e feriados) podem ser considerados dias normais de trabalho, como aponta a entrevistada 03 no fragmento (013).

Examinando, ainda, os mesmos fragmentos propostos, no que se refere às formas de pagamento do ordenado, podemos perceber que acontecem de maneira diferenciada entre as atividades (cortadores e bituqueiras), ou seja, enquanto os homens ganham por produção as mulheres ganham pela diária. Nessa perspectiva, constata-se que as mulheres ficam limitadas a um determinado salário enquanto os homens podem variar de remuneração de acordo com a produção.

(012) [...] a gente ganha pouco, a diária é vinte e nove reais. E ai dar para tira uns mil a novecentos reais. Tem também a cesta básica que sempre vem atrasada. (ENTREVISTADA 02)

(013) [...] o trabalho é cinco por um, às vezes, trabalha domingo, feriado... Não pode pensar muito se não revolta, é estressante [...] a diária de bituca é vinte nove reais, mais tem lugares que é quarenta reais. (ENTREVISTADA 03)

(014) [...] Vinte sete reais por dia, mais o horário de ônibus que elas tiram no valor de cem reais, mais a cesta básica no valor de oitenta reais. [...] A faixa media aqui do salário do cortador de cana é de $R \$ 1400$ reais e aqueles que apresentam a 
produção melhor chegam receber em torno de $\mathrm{R} \$ 2000$ a 3000 por mês [...] (ENTREVISTADO 02).

(015) [...] um fiscal homem ganha 2500 e uma fiscal mulher ganha um pouquinho menos, há uma diferença [...] (ENTREVISTADA 08)

(016) [...] a gente ganha pouco, é a diária, que é tipo um fixo, se faltar perde. Tem também a cesta básica que sempre vem atrasada [...] (ENTREVISTADA 03)

(017) [...] aqui é por escala e a gente ganha é por produção também, a faixa media aqui do salário do cortador de cana é de $\mathrm{R} \$ 1400$ reais e aqueles que apresentam a produção melhor chegam receber em torno de $\mathrm{R} \$ 2000$ a 3000 por mês, mais, por exemplo, e a cesta básica [...] (ENTREVISTADO 10)

A distinção salarial pode ser comprovada no trecho (014) e (015) em que os entrevistados apresentam os valores recebidos por cortadores e bituqueiras. Em tais trechos é possível averiguar, de forma evidente, a discrepância nos valores de remuneração. No fragmento (014) expõe, de maneira clara, a variação do valor recebido. Conforme dito, vê-se que a mais alta remuneração da mulher chega na faixa de mil e novecentos reais, ao passo que o salário dos homens (cortadores) pode chegar a três mil reais. Observa-se, ainda, que os funcionários de corte de cana e bituca trabalham através de escalas, ou seja, suas folgas são de acordo com a escala de trabalho podendo assim trabalhar aos sábados e domingos (fragmentos (016) e (017)). É importante ressaltar que os mesmos, além de terem seus salários diferenciados de acordo com o cargo exercido, tem alguns benefícios tais como a cesta básica.

Cabe ressaltar, ainda, que, mesmo com a participação de mulheres em cargos de gerência, há uma desvalorização salarial em relação ao homem no mesmo cargo como mostra o fragmento (015). Nesse sentido, é valido constatar que mesmo que homens e mulheres estejam no mesmo nível hierárquico, há uma valorização do masculino em relação ao feminino. Isso pode ser percebido nos fragmentos (018) e (019), que destacam tal valorização do masculino referente ao feminino, onde os homens têm mais chance de ascensão na empresa/usinas, e as mulheres têm menos oportunidade.

(018) [...] os cortadores, os operadores de maquinas e os fiscais são mais homens e as bituqueiras são todos mulheres [...] eu acho que os homens tem mais chances de subirem na empresa, a mulher é muito discriminada é igual no futebol o jogadores tem mais oportunidades $e$ as mulheres são mais discriminadas [...] (ENTREVISTADA 01)

(019) [...] tem fiscal, cortador mais é homem. Eu acho que o fiscal homem tem mais prestígio do que uma fiscal mulher, porque acho que respeitam mais os homens [...] quase não dão oportunidade para as mulheres aqui na empresa, pois em outras 
usinas eu já vi tratorista, fiscal e supervisora mulher e trabalhando melhor do que muitos homens [...] (ENTREVISTADA 02)

(020) [...] já teve fiscal mulher aqui na usina. [...] no começo elas não aceitaram porque disse que não iam deixa uma mulher mandar em mim não. Mais aí foi indo, e foi indo e aceitou ne [...] o fiscal homem reconhece o trabalho da gente mais do que a própria mulher [...] (ENTREVISTADA 03)

(021) [...] e o fiscal é mais homem porque eu acho que a gente obedece mais a autoridade do homem mais do que a da mulher, ele da mais assim confiança para a gente trabalhar, você não tem medo chegar nele e conversar [...] (ENTREVISTADA 04)

Vale salientar, ainda, que há uma predominância masculina nos cargos da organização /usinas tais como: cortadores, operadores de máquinas, fiscais (fragmentos (018) e (019)). Quando é verificada uma exceção dessa predominância (fragmentos 020 e 021), não há reconhecimento do trabalho feminino. Nessa perspectiva, é possível afirmar que as próprias mulheres aceitam a dominação masculina, pois já estão com o pensamento masculino, modificado/ estipulado, na qual a figura masculina tem autoridade, status e repassa confiança na sua liderança.

Nos fragmentos discursivos (022) e (023) pode ser entendido, ainda, que a figura da mulher seja incapaz de exercer cargos de gerência na empresa (usina). Sendo, então, o campo feminino inferiorizado e o campo masculino valorizado e os melhores trabalhos são destinados aos homens. Os cargos de chefia e comando (ou hierarquicamente superiores aos das bituqueiras) são essencialmente masculinos.

(022) [...] é porque tinha intimidade com chefe [...] intimidade com chefe é porque o chefe lá da usina é tudo alagoana né ai quando vem pra cá ai começa a conhecer as mulher daqui né ai as fiscal arrumar mulher pra ele [...] (ENTREVISTADA 05)

(023) [...] uai, tem que ter um padrinho bem forte viu, para consegui chega La, se não chega não. (risos)[...] (ENTREVISTADA 04)

Percebe-se, no fragmento discursivo (022), que para a figura feminina, em sua maioria, não há políticas de progressão na carreira e que estas, quando tem um cargo diferenciado, tem sua posição justificada pelo uso do corpo. Pode se afirmar que o corpo feminino é entendido, então, como um objeto, um material passível de negociação, um produto. Analisando o fragmento (023) podemos observar que a ascensão feminina se daria, portanto, pela influência de algum homem que esteja em cargos hierárquicos superiores. Podemos apontar ao relacionarmos estes dois fragmentos propostos ((022) e (023)) que a progressão hierárquica da mulher dentro da empresa/usina ocorre apenas com o auxílio de um símbolo mais forte (o masculino). 
No que tange o processo de treinamento, e visto que há displicência tanto no serviço de cortador quanto na bituca.

(024) [...] cortar é mais é na prática mesmo [...] mais quando comecei lá agente aprendi sozinho, olhando os mais velhos a trabalhar, as vezes o fiscal vem e fala e desse jeito [...] (ENTREVISTADO 08)

(025) [...] o fiscal na época da gente punha uma novata com uma que já era experiente então aquela que já trabalhou ensinava a gente a trabalhar, então não foi uma coisa muito difícil de aprender [...] (ENTREVISTADA 06)

No que diz respeito às possibilidades de treinamento no âmbito do espaço do trabalho, identifica-se que para a maioria dos trabalhadores não há treinamento, ou seja, os mesmos vão aprendendo com a prática, com o exercício do dia a dia. A figura do fiscal é presente e serve como apoio caso alguém precise, conforme pode ser observado nos trechos (024 e 025).

Verificou-se, a partir das discussões propostas, que em certos processos, há uma diferença sexual, enquanto em outras não há diferenciação. A progressão da carreia é um processo que, como visto anteriormente, é sexualizado, onde os homens possuem uma maior possibilidade de ascensão em relação às mulheres. Todavia, é visto a partir da análise dos processos de treinamento, que esta divisão sexual não acontece em todos os espaços, uma vez que o treinamento se mostra igual (ausente) para ambos os gêneros.

\section{CONSIDERAÇÕES FINAIS}

O objetivo deste trabalho consistiu em analisar a dominação masculina e a violência simbólica existente na atividade do corte de cana-de-açúcar na microrregião de Ituiutaba/MG. Para tanto, foram analisadas quinze entrevistas, nas quais cortadores, bituqueiras e sindicalistas, relataram suas experiências no trabalho, colaborando e enriquecendo a o trabalho realizado.

Percebemos, a partir da análise dos dados, a dimensão e a interferência do masculino dentro destas organizações. Vale salientar, ainda, que a partir da análise das políticas oficiais das organizações, verificouse como a dominação ocorre tanto de maneira estrutural (nas políticas de progressão de carreira) quanto de maneira simbólica (no próprio exercício de reprodução dos rituais).

Cabe ressaltar, ainda, que a pesquisa é exploratória e inicial, sendo necessário, ainda, que sejam realizadas novas pesquisas, especialmente aquelas relacionadas a forma como a violência e a dominação ocorrem em vários espaços, tanto no aspecto privado (da casa), como na sociedade, entre outros

\section{Agradecimentos}

Agradecemos ao Conselho Nacional de Desenvolvimento Científico e Tecnológico (CNPQ), bem como a Fundação de Amparo à Pesquisa do Estado de Minas Gerais (FAPEMIG) pelo apoio na realização da pesquisa que deu origem a este artigo. 


\section{REFERÊNCIAS}

ALCADIPANI, Rafael. (2010). Violência e masculinidade nas relações de trabalho: imagens do campo de pesquisa etnográfica. Cadernos Ebape.br, v. 8, n. 1, p.93-110.

BARROS, A. J. S.; LEHFELD, N. A. S. (2007). Fundamentos de metodologia científica (3.ed). São Paulo: Pearson Prentice Hall.

BARROS, A. J. S.; LEHFELD, N. A. S. (1990). Projetos de Pesquisa:Propostas metodológicas. Petropolis: Ed. Vozes. BOURDIEU, Pierre. (2002). A Dominação Masculina. Rio de Janeiro: Bertrand Brasil.

CAMPOS, D. C. (2007). A Análise de Conteúdo na pesquisa qualitativa. Em: BAPTISTA, M. N.; CAMPOS, D. C. (orgs). Metodologias de Pesquisa em Ciências Análises Quantitativa e Qualitativa. Rio de Janeiro: LTC.

COOPER, D. R.; SCHINDLER, P. S. (2011). Métodos de pesquisa em administração. (10.ed). Porto Alegre: Bookman.

GODOI, C. K.; MELLO, R. B.; SILVA, A. B. (2010). Pesquisa qualitativa em estudos organizacionais: paradigmas, estratégias e métodos. (2.ed). São Paulo: Saraiva.

ROSA, Alexandre Reis; BRITO, Mozar José de. (2009). Ensaio Sobre a Violência Simbólica nas Organizações. Organização \& Sociedade, v. 16, n. 51, p.629-646. 